\title{
Photolysis of Polyamides Containing Thymine Photodimer Units in the Main Chain and Application to Deep-UV Positive Type Photoresists
}

\author{
Minoo Jalili Moghaddam, Yoshiaki InaKI, and Kiichi TAKEMOTO \\ Department of Applied Fine Chemistry, Faculty of Engineering, \\ Osaka University, Suita, Osaka 565, Japan
}

(Received December 8, 1989)

\begin{abstract}
Polyamides containing thymine photodimer units in the main chain were found to be applicable to a positive-chain scission type photoresist upon deep-UV exposure. Photo-dissociations of cyclobutane-type photodimers of thymine units caused the scission of the polymer chains, leading to decrease in molecular weight of the polymers. Photolithographic sensitivity and resolution test for these polymers indicated good sensitivity values with novel resolution of even $0.3 \mu \mathrm{m}$.
\end{abstract}

KEY WORDS Photodimerization / Thymine Photodimer /Polyamide / Photodissociation /Deep UV Photoresist / Photoresist / Photosensitivity / High Resolution / Positive Type Photoresists /

Positive photoresists are particularly attractive for VLSI device fabrication due to their high resolution. Most of the positive photoresists used for conventional photolithography are two-component dissolution inhibition resists. The best known conventional photoresist is based on the use of novolac (phenol formaldehyde) polymer with a diazonaphthoquinone photosensitive dissolution inhibitor, using light in the range of $350-450 \mathrm{~nm} .^{1,2}$ However, alternative inhibitors for these systems can afford bleachable chromophores for deep-UV light. ${ }^{3,4}$ The other positive type photoresists are chain scission polymers. Poly(methyl methacrylate) is a classic positive resist with high resolution upon deep-UV exposure. However, it has low sensitivity, which has been improved by copolymerization of methyl methacrylate with more absorbant UV sensitive components. ${ }^{6}$

Recently, we reported the successful synthesis of a new type of chain scission positive type photoresist based on polyamide containing thymine photodimer units in the main chain, and its photochemical reaction. In the synthesis of this polymer, thymine photodimer derivative prepared by photochemical reaction of the monomeric compound was reacted with 1,3-diamino propane in a condensation polymerization. The separated isomers of thymine photodimer applied in the synthesis of the polyamide did not cause considerable change in the polymer structure or its photochemical reaction. Lithographic resolution and sensitivity of these polymers upon deep-UV exposure are demonstrated in this article. Furthermore, we synthesized six types of polyamides containing thymine photodimer units with different diamines. We studied the effects of the diamine structures on the morphology of the polymers such as glass transition temperatures and melting points, which are important in the photodissociation of these polymers. Photolithographic evaluation of these polymers was also studied. 


\section{EXPERIMENTAL}

\section{Materials}

The polyamides (4) were prepared from thymine photodimer derivative (2) and various diamines (Scheme 1) through activated ester method, as described in our earlier report. ${ }^{7}$ The yieds of the polyamides and the IR spectral bands are tabulated in Table I. Also, their structures were confirmed by elementary analysis and ${ }^{1} \mathrm{H}$ NMR spectra given in Tables II and III. Molecular weight and the $M_{w} / M_{n}$ values obtained by gel permeation chromatography (GPC) method are tabulated in Table IV.
Table I. Yields and infrared spectra data of the polyamides

\begin{tabular}{ccccccccc}
\hline Polymer $\begin{array}{c}\text { Yield/ } \\
\%\end{array}$ & \multicolumn{1}{c}{ Infrared absorption band $/ \mathrm{cm}^{-1}$} \\
\hline 4a & 79.4 & 3450 & 3220 & 2935 & 2850 & 1700 & 1620 \\
& & 1520 & 1470 & 1370 & 1280 & 1240 & \\
4b & 76.0 & 3300 & 3075 & 2950 & 2840 & 1700 & 1650 \\
& & 1530 & 1475 & 1435 & 1360 & 1285 & 1240 \\
4c & 81.1 & 3500 & 3250 & 3050 & 1700 & 1600 & 1510 \\
& & 1475 & 1405 & 1295 & 1235 & & \\
4d & 71.3 & 3500 & 3250 & 3075 & 1700 & 1595 & 1535 \\
& & 1480 & 1400 & 1295 & 1210 & & \\
4e & 48.0 & 3300 & 3150 & 3075 & 1695 & 1645 & 1500 \\
& & 1470 & 1395 & 1230 & 1210 & 980 & \\
4f & 95.0 & 3300 & 3080 & 2950 & 1700 & 1620 & 1540 \\
& & 1470 & 1380 & 1250 & 840 & 790 &
\end{tabular}

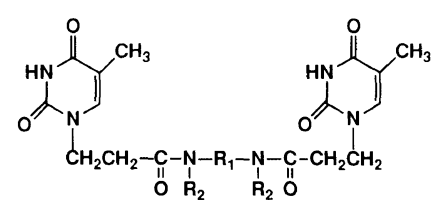

(3)

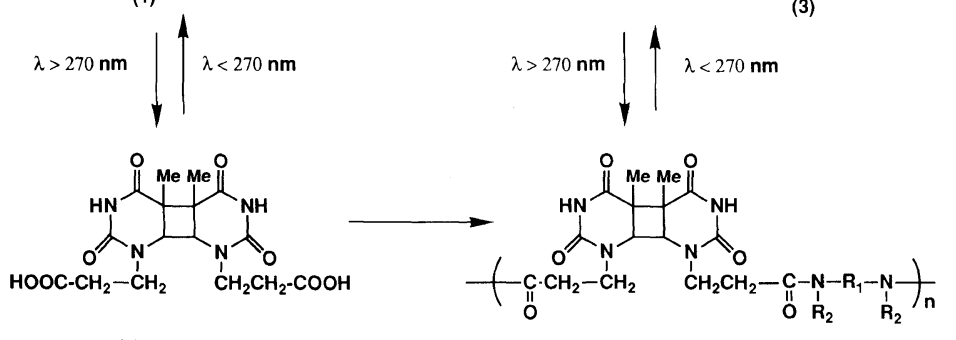

(2)

(4)

$$
\mathbf{R}_{1} \quad \mathbf{R}_{\mathbf{2}}
$$

C

Scheme 1. 
Photolysis of Polyamides Containing Thymine Photodimer Units in Main Chain

Table II. Analytical data for the polyamides containing thymine photodimer

\begin{tabular}{|c|c|c|c|c|c|c|c|}
\hline & \multirow{2}{*}{ Polymer } & \multicolumn{3}{|c|}{ Calcd $/ \%$} & \multicolumn{3}{|c|}{ Found $/ \%$} \\
\hline & & $\mathrm{C}$ & $\mathbf{H}$ & $\mathbf{N}$ & $\mathrm{C}$ & $\mathbf{H}$ & $\mathrm{N}$ \\
\hline $\mathbf{4 a}$ & $\mathrm{C}_{29} \mathrm{H}_{42} \mathrm{~N}_{6} \mathrm{O}_{6}$ & 61.03 & 7.41 & 14.72 & 61.42 & 7.36 & 14.29 \\
\hline $4 b$ & $\mathrm{C}_{26} \mathrm{H}_{40} \mathrm{~N}_{8} \mathrm{O}_{6}$ & 55.70 & 7.19 & 20.00 & 56.44 & 7.09 & 19.15 \\
\hline $4 c$ & $\mathrm{C}_{29} \mathrm{H}_{30} \mathrm{~N}_{6} \mathrm{O}_{6}$ & 62.35 & 5.05 & 15.04 & 62.26 & 5.29 & 14.65 \\
\hline 4d & $\mathrm{C}_{28} \mathrm{H}_{28} \mathrm{~N}_{6} \mathrm{O}_{7}$ & 60.0 & 5.03 & 14.99 & 59.25 & 5.29 & 14.86 \\
\hline $4 e$ & $\mathrm{C}_{30} \mathrm{H}_{34} \mathrm{~N}_{6} \mathrm{O}_{8} \mathrm{Si}$ & 56.76 & 5.39 & 13.25 & 55.94 & 7.12 & 13.02 \\
\hline $4 f$ & $\mathrm{C}_{26} \mathrm{H}_{44} \mathrm{~N}_{6} \mathrm{O}_{7} \mathrm{Si}_{2}$ & 51.30 & 7.28 & 13.80 & 51.70 & 7.42 & 13.16 \\
\hline
\end{tabular}

Table III. ${ }^{1} \mathrm{H}$ NMR spectral data of polyamides containing thymine photodimers (ppm)

\begin{tabular}{cccccl}
\hline Polymer & $\mathrm{C}^{5}-\mathrm{CH}_{3}$ & $\mathrm{CH}_{2}-\mathrm{C}=\mathrm{O}$ & $\mathrm{N}-\mathrm{CH}_{3}$ & $\mathrm{O}=\mathrm{C}-\mathrm{NH}$ & \multicolumn{1}{c}{ Amine related } \\
\hline $\mathbf{4 a}$ & $1.34,1.48$ & $3.68,4.0$ & 3.2 & - & $1.28,2.64,2.78$ \\
$\mathbf{4 b}$ & $1.36,1.51$ & $3.64,4.0$ & 3.12 & 7.47 & 1.66 \\
$\mathbf{4 c}$ & $1.30,1.48$ & $3.60,3.90$ & 3.14 & 9.5 & $2.62,7.16,7.46$ \\
$\mathbf{4 d}$ & $1.38,1.50$ & $3.64,3.90$ & 3.4 & 9.64 & $7.00,7.32,7.52$ \\
$\mathbf{4 e}$ & $1.30,1.48$ & $3.64,3.90$ & 3.4 & 9.65 & $6.7,7.3$ \\
$\mathbf{4 f}$ & $1.34,1.49$ & $3.64,4.0$ & 3.3 & 7.42 & $3.14,0.62$ \\
\hline
\end{tabular}

Table IV. GPC data of polyamides containing thymine photodimer units

\begin{tabular}{ccc}
\hline Polymer & $M_{n}$ & $M_{w} / M_{n}$ \\
\hline 4a & 19950 & 1.55 \\
$\mathbf{4 b}$ & 22000 & 1.50 \\
$\mathbf{4 c}$ & 23980 & 1.54 \\
$\mathbf{4 d}$ & 17418 & 1.40 \\
$\mathbf{4 e .}$ & 7988 & 1.32 \\
$\mathbf{4 f}$ & 3660 & 1.30 \\
\hline
\end{tabular}

\section{Photolysis}

Photolyses of these polymers were carried out in the film state. The polymers $(\mathbf{4 a}-\mathbf{4 e})$ were dissolved in dimethylformamide and the polymer $4 \mathrm{f}$ was dissolved in a mixture of aceton-methanol to obtain good solutions for casting on quartz substrates. The solutions of these polymers $(10 \%, \mathrm{w} / \mathrm{w})$ were cast on quartz substrates, and the solvents were removed under reduced pressure for $24 \mathrm{~h}$ to obtain polymer films of $1-2 \mu \mathrm{m}$ thick. Photolyses of the polymer films were carried out using both a low-pressure mercury lamp with main intensity at $254 \mathrm{~nm}$ and a Nihon-Bunko (CRM-FA) spectroirradiator equipped with a $2 \mathrm{~kW}$ Xe-Arc lamp, the light of which was passed through a diffracting latticed window to obtain narrow wavelengths of $249 \pm 1 \mathrm{~nm}$ as the light source. The photochemical reaction was followed by absorbance at $270 \mathrm{~nm}$ which is related to the formation of thymine monomer units.

Typical depiction of the photodissociation spectra of polyamide $\mathbf{4 a}$, monitored at regular intervals is shown in Figure 1. The photodissociation and photodimerization of thymine photodimer units occurred reversibly. However, until the establishment of a quasiequilibrium condition, the photodissociation reaction substantially occurred. ${ }^{10}$ Therefore, after a regular exposure dose, an equilibrium condition with no more increase in the absorbance spectra would be obtained $\left(A_{\mathrm{e}}\right){ }^{7}$ The relation between the absorbance at different photolysis time and the absorbance 


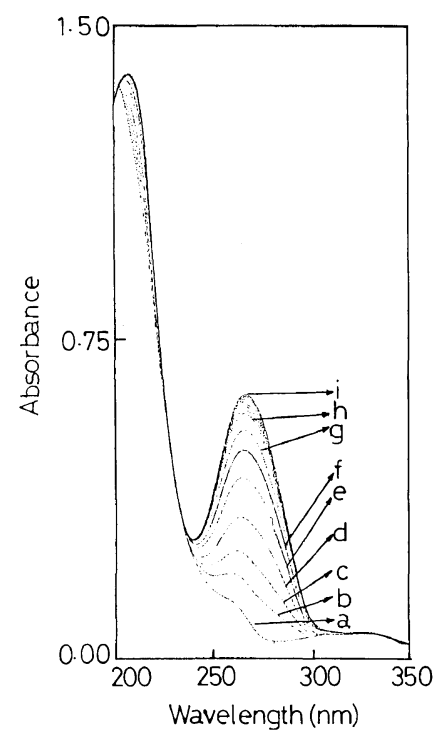

Figure 1. The UV absorption spectra of polymer 4a upon irradiation of deep-UV light at $249 \mathrm{~nm}$. a) before irradiation, b-i) after irradiation of $21,43,86,150,214$, 278,363 , and $513 \mathrm{~mJ} \mathrm{~cm}^{-2}$ doses, respectively, based on $249 \mathrm{~nm}$ UV light.

at equilibrium is as follows. ${ }^{7}$

$$
-\ln \left\{\left(A_{\mathrm{e}}-A\right) / A_{e}\right\}=K_{1} t / X_{\mathrm{e}}
$$

where $A$ and $A_{\mathrm{e}}$ are the absorbance at $270 \mathrm{~nm}$ after an exposure time $(t)$ and the equilibrium absorbance, respectively; $K_{1}$ is the rate constant of photodissociation; and $X_{\mathrm{e}}$ is the equilibrium conversion of thymine photodimer to thymine monomer. The ratios of the photodissociation rate constant to the equilibrium conversion $\left(K_{1} / X_{\mathrm{e}}\right)$ can be obtained by plotting of $-\ln \left\{\left(A_{\mathrm{e}}-A\right) / A_{\mathrm{e}}\right\}$ against the exposure time.

If the absorbed light is expressed as the exposure dose, eq 1 can be reformed to obtain eq 2 .

$$
-\ln \left\{\left(A_{\mathrm{e}}-A\right) / A_{\mathrm{e}}\right\}=\sigma_{1} L / X_{\mathrm{e}}
$$

where $\sigma_{1}$ is the cross section and $L$ is the exposure dose. The relation between a cross section and quantum yield of the photodissociation $(\Phi)$ is as eq $3 .^{11}$

$$
\Phi=\sigma_{1} / 2.303 \times 10^{-3} \varepsilon
$$

The ratios of the photodissociation cross section to the equilibrium conversion $\left(\sigma_{1} / X_{\mathrm{e}}\right)$ can be obtained by plotting of $-\ln \left\{\left(A_{\mathrm{e}}-A\right)\right.$ / $\left.A_{\text {e }}\right\}$ against the exposure dose.

\section{Lithographic Testing}

Lithographic Sensitivity. The photosensitivity spectra were recorded by a Nihon spectrophotograph (CT-40) equipped with a 500 W Xe-short Arc lamp as the deep-UV source. A solution of the polyamide in dimethylformamide was spin coated on silicon wafers, and the wafers were exposed to the irradiation of a UV light spectrum through the thin slit of a spectrophotograph. The wafers were scanned up against the light slit at a specified time and developed for $1 \mathrm{~min}$ in a mixture of 2-propanol-methanol $(7: 3)$, followed by rinsing in $n$-butyl acetate for 1 more min. The minimum required energy was evaluated as the least energy for removing the irradiated part after development. ${ }^{9}$

Lithographic Resolution. A Cannon mask aligner (PLA-521F) equipped with cold mirror (CM250), and a Xe-Hg lamp as the light source were used for resolution evaluation. A quartz mask (Dai Nihon Insatsu) was applied as the imaging pattern and the irradiation of the wafers was carried out by contact printing method. The solutions of polymers $4 \mathbf{a}-\mathbf{4 e}$ in dimethylformamide (DMF) with different concentration $(10 \%$ and $20 \%, w / w)$ and $4 f$ in aceton-methanol were spin coated on the silicon wafers. Solvents were removed by prebaking at $90^{\circ} \mathrm{C}$ on a hot plate for $1 \mathrm{~min}$ to obtain $0.3 \mu \mathrm{m}$ and $1 \mu \mathrm{m}$ thick films, respectively. The films were exposed through a contact quartz mask to varying doses of deep-UV light reflected on a cold mirror CM-250 which selectively reflects deep-UV light of $250 \mathrm{~nm}$ wavelength of the light. Pattern developments were attempted in various mixtures of methanol-ethanol-2-propanol for 1 min, followed by rinsing in $n$-butyl acetate for 1 more $\mathrm{min}$. 


\section{Instrumentation}

Ultraviolet (UV) spectra were measured with a Nihon-Bunko (UVIDEC-660) spectrophotometer. Glass transition temperature $\left(T_{\mathrm{g}}\right)$ of the polymers was measured with a Seiko Differential Scanning Calorimeter (DSC-20). The molecular weight distribution of the polymers were determined by GPC method using Toyo Soda HLC-CP8000 equipped with a thermostatted column TSK gel G4000HT and a UV detector operating at $270 \mathrm{~nm}$ with dimethylformamide as the eluent.

\section{RESULTS AND DISCUSSION}

\section{Polymer Synthesis}

Photodimerization of the thymine derivatives gives the photodimers (2) of four isomers: cis-syn, cis-anti, trans-syn, and trans-anti. The photochemical reaction of the carboxyethyl derivative of thymine (1) in water with acetone as a sensitizer, however, gave cis-syn and cis-anti photodimers as the main products. It was discussed in our previous report that there was no difference in the polymer dissociation rates for polymers with different isomeric structure of the thymine photodimer. ${ }^{7}$ Therefore, we used a mixture of $c i s$-syn and cis-anti photodimers for the preparation of the polyamides. The diamines used for the preparation of the polyamides had a wide variation in structure and rigidity.

The polyamides $\mathbf{4 c}$ and $\mathbf{4 d}$ which incorporated aromatic moieties in the main chain, showed higher $T_{\mathrm{g}}$ and $T_{\mathrm{m}}$ 's than other polymers (Table V). On the other hand, the polymers $4 \mathbf{e}$ and $4 \mathbf{f}$ containing silicon in the main chain, had low $T_{\mathrm{m}}$ 's; the $T_{\mathrm{g}}$ 's of these polymers could not be measured; however, low $T_{\mathrm{g}}$ values beyond $0^{\circ} \mathrm{C}$ are expected from the melting point data. These results are in accordance with what was expected from the structures of the diamines used in the syntheses of the polyamides. The relatively higher $T_{\mathrm{g}}$ of the former polymers are desired for their thermal stability and etching characteristics.
Table V. Melting point $\left(T_{\mathrm{m}}\right)$ and glass transition temperature $\left(T_{\mathrm{g}}\right)$ data of the polymers

\begin{tabular}{ccc}
\hline Polymer & $T_{\mathrm{m}} /{ }^{\circ} \mathrm{C}$ & $T_{\mathrm{g}} /{ }^{\circ} \mathrm{C}$ \\
\hline $\mathbf{4 a}$ & $212-215$ & 26.7 \\
$\mathbf{4 b}$ & $175-178$ & - \\
$\mathbf{4 c}$ & $258-261$ & 72.0 \\
$\mathbf{4 d}$ & $243-245$ & 52.5 \\
$\mathbf{4 e}$ & $196-198$ & - \\
$\mathbf{4 f}$ & $150-153$ & - \\
\hline
\end{tabular}

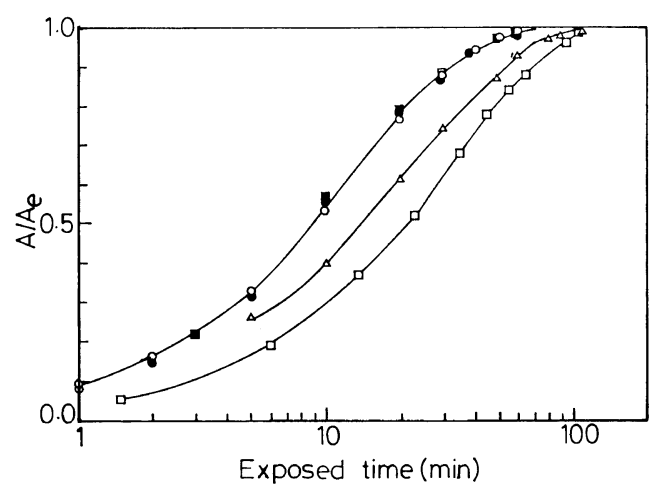

Figure 2. Photodissociation characteristic of polyamides in film state exposed to the UV light of a low pressure mercury lamp as a function of exposure time. $\mathbf{\square}, \mathbf{4 a} ; \square$, 4b; $\bigcirc, 4 c ; \bigcirc, 4 d ; \triangle, 4 f$.

However, due to the intrinsic absorption of the aromatic units, light passing through the thickness of the polymer film may decline, and hence poor resist profiles be obtained. Although the incorporation of silicon into a polymer increases the polymer resistance to erosion in oxygen plasma, a decrease in $T_{\mathrm{g}}$ of the polymer usually occurred at the same time. ${ }^{8}$ The low $T_{\mathrm{g}}$ of silicon containing polyamides may cause problems such as image creep during photolithographic processes. However, these polymers might be used in multilevel, reactive ion etching pattern transfer processes.

\section{Photolysis}

Photolysis by a Low-Pressure Mercury Lamp. The results of the photodissociation reactions of the polyamides are plotted in Figures 2 and 3. It is apparent from Figure 2 that polymers 


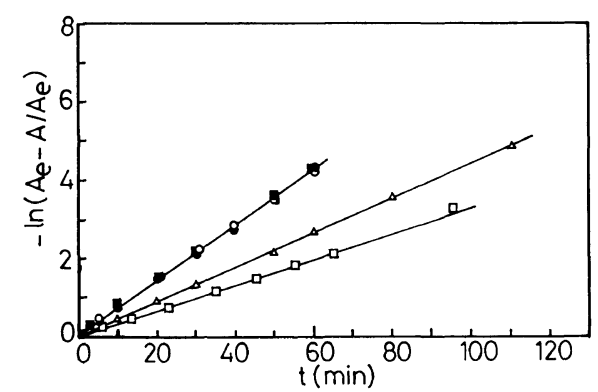

Figure 3. Kinetics of photodissociation of polyamides in film state. $A_{\mathrm{e}}$, the quasi-equilibrium absorbance at $270 \mathrm{~nm}$ upon irradiation of deep-UV light of a low pressure mercury lamp; $\square, \mathbf{4 a} ; \square, \mathbf{4 b} ; 0, \mathbf{4 c} ; \bigcirc, \mathbf{4 d} ; \triangle, \mathbf{4 f}$.

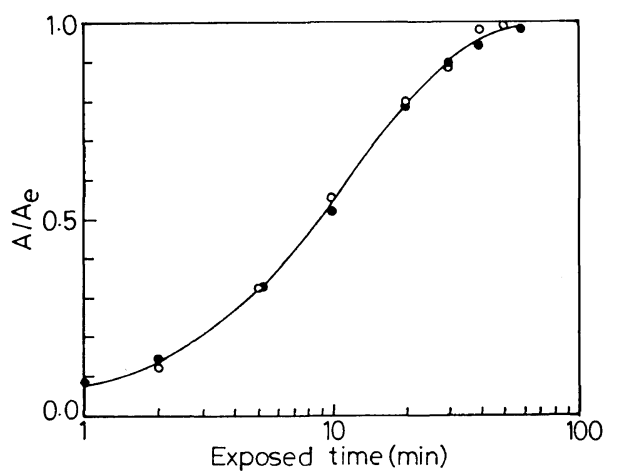

Figure 4. Photodissociation characteristic of polymer $\mathbf{4 c}$ with different film thicknesses. $O, 0.3-0.4 \mu \mathrm{m}$; $0.7-0.8 \mu \mathrm{m}$.

4a, $4 \mathbf{c}$, and $4 d$ attain a photosteady state faster than polymers $\mathbf{4 b}$ and $\mathbf{4 f}$. The straight lines with steeper slopes (Fig. 3) gave higher values of $K_{1} / X_{\mathrm{e}}$ (Figure 3). The higher value of $K_{1} / X_{\mathrm{e}}$ might be not only due to the higher values of the $K_{1}$, but also to the lower values of the equilibrium conversion. However, it is difficult to determine the photodissociation rates by low pressure mercury lamp, since there is some irradiation around the wavelength $310 \mathrm{~nm}$, which might cause further photodimerization of the photodissociated thymine in the polymer chains.

It should be also noted that the photodissociation rate of these polymers did not depend on the thicknesses of the films as shown in Figure 4 for polymer $\mathbf{4 c}$.

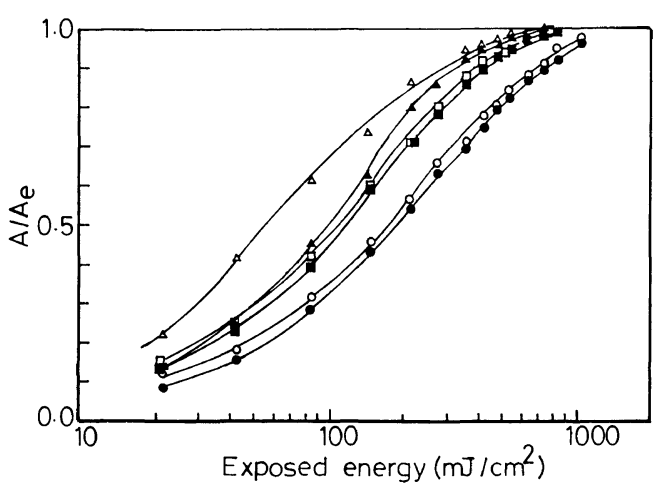

Figure 5. Photodissociation characteristic of polyamides in film state exposed to the UV light of a monochromatic light at $249 \mathrm{~nm}$ as a function of exposure dose. $\square, 4 \mathbf{4 a} \square$, $\mathbf{4 b} ; \bigcirc, \mathbf{4 c} ; \bigcirc, \mathbf{4 d} ; \Delta, \mathbf{4 e} ; \triangle, \mathbf{4 f}$.

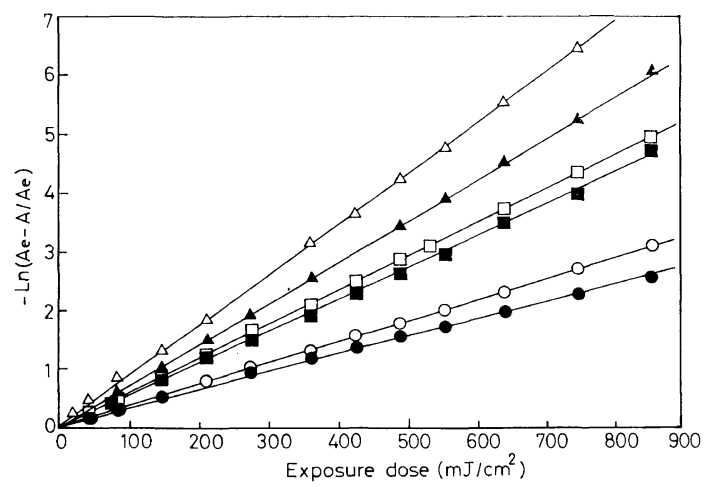

Figure 6. Kinetics of photodissociation of polyamides in film state. $A_{\mathrm{e}}$ : the quasi-equilibrium absorbance at $270 \mathrm{~nm}$ upon exposure of a monochromatic light at $249 \mathrm{~nm}$ : $\square$, 4a, $\square, \mathbf{4 b} ; \bigcirc, \mathbf{4 c} ; \bigcirc, \mathbf{4 d} ; \Delta, \mathbf{4 e} ; \triangle, \mathbf{4 f}$.

Photolysis by a Monochromatic Light. The irradiation of the monochromatic light at $249 \mathrm{~nm}$ was used due to the coincident irradiation of a $\mathrm{KrF}$ excimer laser. However, to eliminate the rephotodimerization as much as possible, irradiation at a wavelength lower than $240 \mathrm{~nm}$ was required, where the optical absorbance of the photodimers of thymine bases was at least equal or higher than their monomers. Figures 5 and 6 show the results of the photodissociation reactions. It is revealed from these figures that the dissociation rates of the polymers with lower $T_{\mathrm{g}}$ are higher 


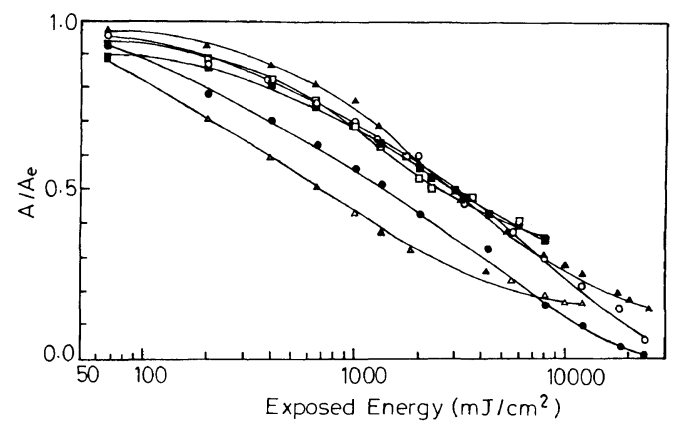

Figure 7. Rephotodimerization characteristic of the photodissociated polyamides in the film state upon exposure to a monochromic light at $280 \mathrm{~nm}$ : $\square, 4 \mathbf{4 a} ; \square$, 4b; $, \mathbf{4 c}, \bigcirc, \mathbf{4 d}, \Delta, \mathbf{4 e} ; \triangle, \mathbf{4 f}$.

than those of polymers with higher $T_{\mathrm{g}}$. This result may be related to the fact that the photoreactions were carried out at room temperature, and therefore polyamides with $T_{\mathrm{g}}$ lower than room temperature had more conformational freedom of the polymer chains; the more the photodissociated thymine is fixed in a suitable position for photodimerization, the lower is the rate of the photodissociation.

The sequence of the results in Figure 6 is different from that of Figure 3. This might be due to the emission of the longer wavelengths of the low pressure mercury lamp, which causes further photodimerization of the thymine base.

The above results indicate that the wavelength of the light should be as narrow as possible for the photodissociation of polymers containing thymine photodimers in the main chain. Therefore, an excimer laser $(\mathrm{KrF}$, $249 \mathrm{~nm}$ ) may be suitable as a light source for the photodissociation of the polyamides containing thymine photodimer. The results of the rephotodimerization of the polymer films after the quasi-equilibrium state, irradiated with the monochromic light centered at $280 \mathrm{~nm}$, are also shown in Figure 7. The polymer 4 f incorporating silicon with aliphatic groups showed higher reaction rates than other polymers. However, the polymers with aromatic groups and higher $T_{\mathrm{g}}(\mathbf{4 c}, \mathbf{4 d})$ showed almost complete recovery of the parent

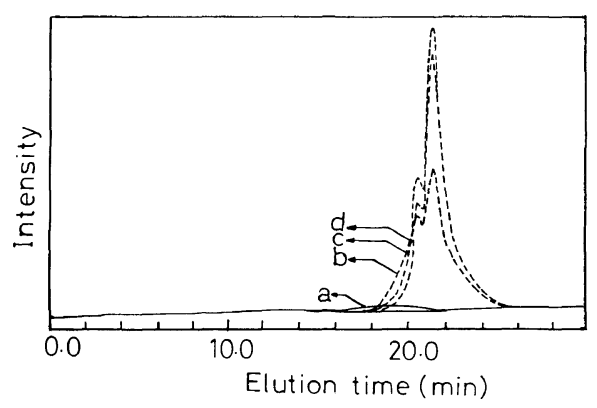

Figure 8. Molecular weight distribution of polyamide 4a upon irradiation of UV light at $249 \mathrm{~nm}$, a) before irradiation, b), c), and d) after irradiation of 107, 214, and $427 \mathrm{~mJ} \mathrm{~cm}^{-2}$ doses, respectively.

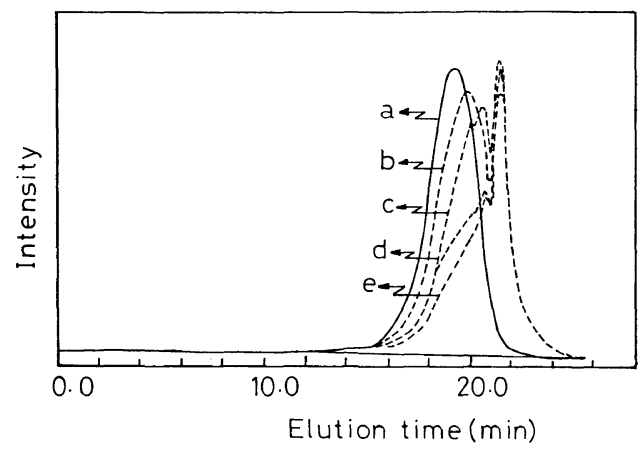

Figure 9. Molecular weight distribution of polyamide $\mathbf{4 c}$ upon irradiation of UV light at $249 \mathrm{~nm}$, a) before irradiation, b-e) after irradiation of $107,320,643$, and $965 \mathrm{~mJ} \mathrm{~cm}^{-2}$ doses, respectively.

absorbance, indicating a fixed suitable position of the photodissociated bases for rephotodimerization reaction.

GPC Study of the Polymers. The results of the GPC measurements for the unirradiated polymers are given in Table IV. After the polymer films were irradiated at regular doses, they were dissolved in dimethylformamide and the molecular weights were measured. Typical results for the polymers $\mathbf{4 a}$ and $\mathbf{4 c}$ are shown in Figures 8 and 9. It is revealed from these figures that photolyses of the polymers caused chain scission, leading to the appearance of the oligomers containing thymine bases at the end of the molecules. However, since the GPC measurements were detected by UV detector operating at $270 \mathrm{~nm}$, a quantitative measure- 
ment of the chain scission rate could not be obtained due to different optical absorbances of the thymine photodimer and thymine monomer units.

\section{Lithographic Testing}

Lithographic Sensitivity. A primary photosensitivity test was carried out for three polyamides containing 1,3-diaminopropane and thymine photodimer, cis-anti, cis-syn, and a mixture of the isomers; the photoreaction of which has been already reported. ${ }^{7}$ However, a lithographic test of the polymer containing cis-syn isomer was not successful due to its poor solubility. The photosensitivity spectra gave the photo-sensitivity range and minimum required energy for photodissociation of the polymers and their solubility in the developer. Figure 10 shows that the minimum required energy for both of those polymers at different wavelengths were nearly the same, and the least energy required for complete removal of the irradiated parts occurred at wavelength $250 \mathrm{~nm}$. This indicates that the polyamide containing the thymine photodimer can be applied as a suitable positive-type photoresist for excimer laser $(\mathrm{KrF})$ with narrow wavelength at $249 \mathrm{~nm}$.

Lithographic Resolution. A positive image was obtained by pattern developments with mixtures of methanol-ethanol-2-propanol for $1 \mathrm{~min}$, followed by rinsing in $n$-butyl acetate for 1 more min. Figure 11 shows a clear positive-tone image obtained from the polyamide 4 containing the thymine photodimer (cis-anti isomer) and 1,3-diaminopropane. The amount of energy required for this pattern transfer was $345.6 \mathrm{~mJ} \mathrm{~cm}^{-2}$ based on the $250 \mathrm{~nm}$ probe of the exposure monitor. Lines and spaces of even $0.5 \mu \mathrm{m}$ were clearly resolved; this resolution was the limit on the applied mask.

Similar processes were carried out for polyamides $4 \mathbf{a}-\mathbf{4 f}$. Typical images obtained for polymers $\mathbf{4 a}$ and $\mathbf{4 c}$ are shown in Figures 12 and 13. The applied masks used in the

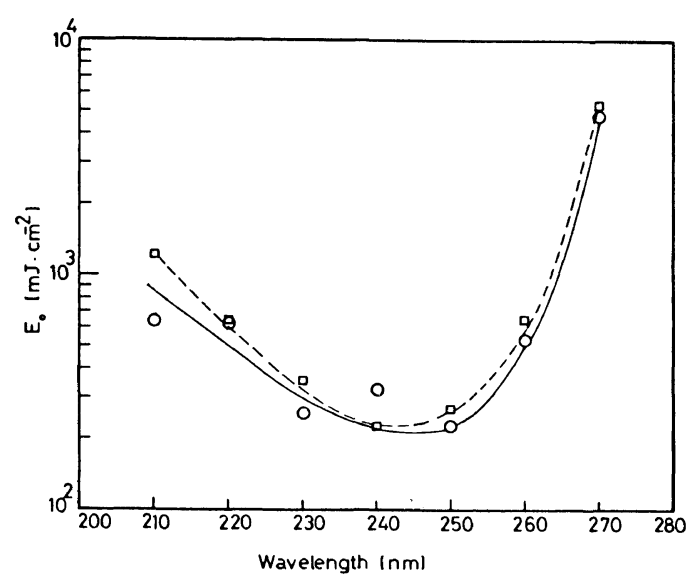

Figure 10. Photolithographic sensitivity spectra of polyamide containing 1,3-diamino propane and different isomers of thymine photodimer: $\bigcirc$, cis-anti isomer; cis-syn and cis-anti mixed isomers. ${ }^{7}$

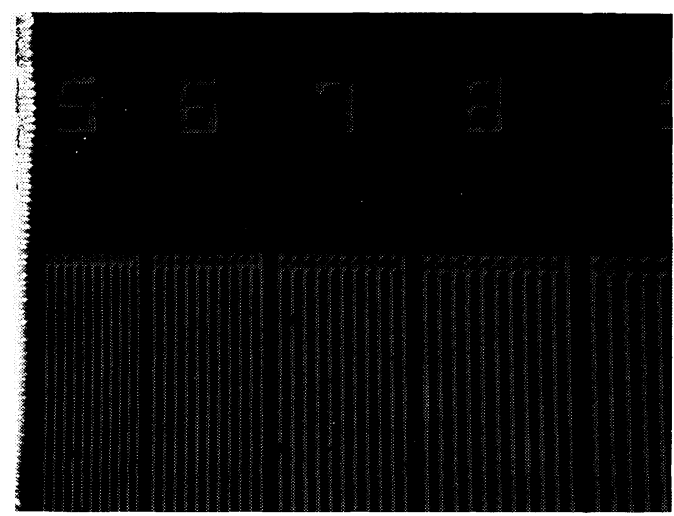

Figure 11. Resolution pattern of polyamide containing 1,3-diamino propane and thymine photodimer. Film thickness, $0.3 \mu \mathrm{m}$; exposure energy, $345.6 \mathrm{~mJ} \mathrm{~cm}^{-2}$; development, methanol-isopropanol: $(2: 8)$ for $1 \mathrm{~min}$. The unit of the figures in the picture is $0.1 \mu \mathrm{m}$.

pattern transferred to these polymers had lines and spaces of even $0.1 \mu \mathrm{m}$. Lines of $0.3 \mu \mathrm{m}$ are clearly resolved in both of these polymers. The film thickness of polymer $\mathbf{4 c}$ was $1 \mu \mathrm{m}$, and it is clear that excellent resolution will be obtained even at this thickness with the same required UV light dose.

For polyamides $4 b, 4 e$, and $4 f$, however, clear images could not be obtained due to the poor adhesion of these polymers to the silicon wafers. 


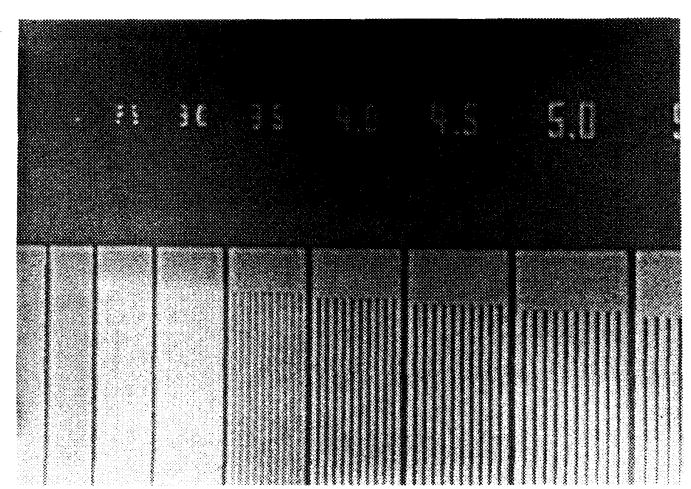

Figure 12. Resolution pattern of polymer 4a. Film thickness, $0.3 \mu \mathrm{m}$; exposure energy, $345.6 \mathrm{~mJ} \mathrm{~cm}^{-2}$; development, methanol-isopropanol $(3: 7)$ for $1 \mathrm{~min}$. The unit of the figure in the picture is $0.1 \mu \mathrm{m}$.

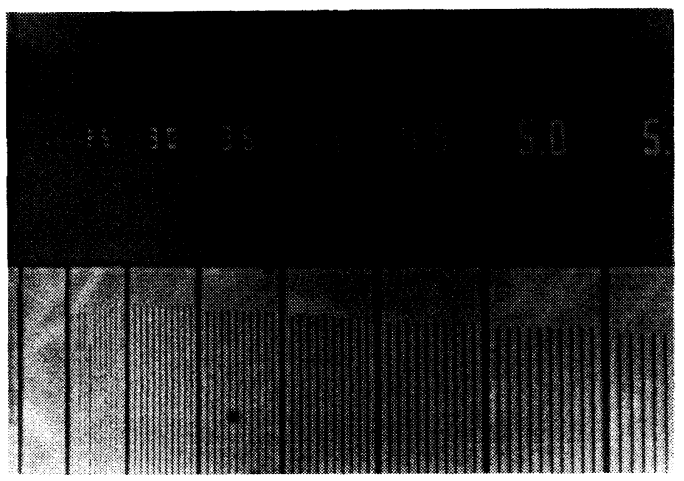

Figure 13. Resolution pattern of polymer 4c. Film thickness, $1 \mu \mathrm{m}$; exposure energy, $345.6 \mathrm{~mJ} \mathrm{~cm}^{-2}$; development, methanol-ethanol $(9: 1)$ for $1 \mathrm{~min}$. The unit of the figures in the picture is $0.1 \mu \mathrm{m}$.

\section{CONCLUSIONS}

Polyamides containing thymine photodimer derivatives and different diamines in the main chain were found applicable to a chain-scission positive type photoresist. The polyamides containing aromatic moieties had high $T_{\mathrm{g}}$ and $T_{\mathrm{m}}$ values, but showed lower photochemical reaction rates in the film state. However, polaymide containing methylene dianiline showed very high resolution values of even $0.3 \mu \mathrm{m}$. The polyamide containing silicon in the main chain had lower $T_{\mathrm{g}}$ and $T_{\mathrm{m}}$, but showed high reactivity in the photodissociation reaction. The irradiation of deep-UV light at $250 \mathrm{~nm}$ gave the highest reactivity in the photodissociation reaction and the highest lithographic sensitivity. Thus, polyamides containing thymine photodimer suitable as resist material for the $\mathrm{KrF}$ excimer laser.

Acknowledgment. The authors wish to express grateful acknowledgment to the Japan Synthetic Rubber Co. for conducting photolithographic tests on the samples.

\section{REFERENCES}

1. C. G. Willson and J. M. J. Frenchet, "Materials for Microlithography” ACS Symposium Series, 1984, p 266.

2. E. Reichmanis and L. F. Thompson, Ann. Rev. Mater. Sci., 17, 235 (1987).

3. B. D. Grant, N. J. Clecak, R. J. Twieg, and C. G. Willson, IEEE Trans. Electron. Dev., 28, 1300 (1987).

4. E. Reichmanis, C. W. Wilkins, Jr., and E. A. Chandross, J. Vac. Sci. Technol., 19, 1338 (1987).

5. Y. Mimura, T. Ohkubo, T. Takenichi, and K. Sekikawa, Jpn. J. Appl. Phys., 17, 541 (1987).

6. C. W. Wilkins Jr., and E. A. Chandross, J. Electrochem. Soc., 127, 2510 (1980).

7. M. J. Moghaddam, S. Hozumi, Y. Inaki, and K. Takemoto, J. Polym. Sci., Poly. Chem. Ed., 26, 3297 (1988).

8. M. Suzuki, K. Saigo, H. Gokan, and Y. Ohnishi, $J$. Electrochem. Soc., 130, 1962 (1983).

9. M. J. Moghaddam, S. Hozumi; Y. Inaki, and K. Takemoto, Polym. J., 21, 203 (1988).

10. G. J. Fisher and H. E. Johns, "Photochemistry and Photobiology of Nucleic Acids," S. Y. Wang, Ed., Vol. I, Academic, New York, N.Y., 1976, p 230.

11. M. A. Herbert, J. C. Leblanc, D. Weinblum, and H. E. Johns, Photochem. Photobiol., 9, 33 (1969). 